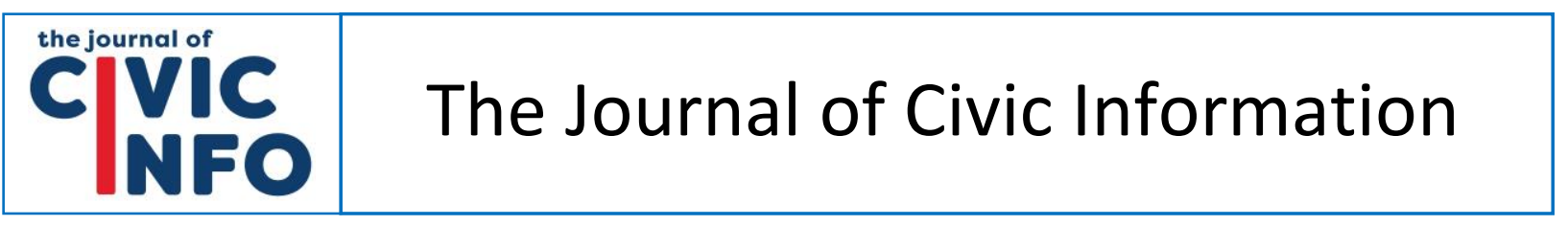

Volume 3 | Number 2

August 2021

Journal homepage: https://journals.flvc.org/civic/

ISSN (online): 2641-970X

\title{
Inherent Frictions and Deliberate Frustrations: Examining the Legal Variables of State FOI Law Administration
}

\section{A.Jay Wagner *}

\section{Article Information}

Received: Feb. 6, 2021

Accepted: July 16, 2021

Published: Aug. 31, 2021

Keywords

Freedom of information

Right to know

Government transparency

FOI

\begin{abstract}
FOI laws are of a category of laws acutely predisposed to internal resistance and erosion. The study seeks to better understand these limitations by examining legal elements of the laws through an exploratory field study, or audit, of nine state FOI laws. Among the study's findings are two uniquely strong predictors of better FOI results: The existence of an independent FOI advocacy organization in the state and a legislature subject to the law. The findings suggest cultivating a culture of transparency may be as or more important than any of the generally considered legal variables, such as deadlines or penalties.
\end{abstract}

* A.Jay Wagner is an assistant professor in the Marquette University Diederich College of Communication. The article would not have been possible without the research assistance of Elizabeth Castellano, Kayla Gonzalez, Christina Mazzeo, and Molly O’Brien, each integral in the audit process. Ryan Barelli was indispensable in managing the project's data.

To cite this article in Bluebook: A.Jay Wagner, Inherent Frictions and Deliberate Frustrations: Examining the Legal Variables of State FOI Law Administration, 3 J. CIVIC INFO 2, 29 (2021).

To cite this article in APA: Wagner, A.J. (2021). Inherent Frictions and Deliberate Frustrations: Examining the Legal Variables of State FOI Law Administration. Journal of Civic Information, 3(2), 29-49.

DOI: 10.32473/joci.v3i2.127815

Published under Creative Commons License CC BY-NC, Attribution NonCommercial 4.0 International. 


\section{Introduction}

On Feb. 28, 2018, WSB-TV in Atlanta submitted a request under the Georgia Open Records Act (ORA) for water billing information for the residence of Mayor Kasim Reed, a property rented by the mayor from his brother (Klepal \& Deere, 2018). Reporting would show that this request spurred expletive-laden text messages between the mayor's spokesperson, Jenna Garland, and the head of communications at the Watershed Department. The request had uncovered thousands of dollars in unpaid water bills, a neglected disconnect notice and an ongoing investigation into water theft. When Garland asked whether a response had been issued, Lillian Govus, the communications manager for the Watershed Department, assured her, "Fuck no," she wrote. "I ain't stupid." Garland provided Govus with orders on how to handle the request, instructing Govus to "be as unhelpful as possible" and to "drag this out as long as possible," and concluding the exchange by encouraging Govus to "provide the information in the most confusing format possible." In a subsequent request for city council members' water bills, Govus was told not to deliver the requested records until the WSB-TV producer followed up on the request, even if the records were ready to be released (Trubey, 2019). The records would not be released until the television station hired a lawyer to threaten legal action. The Georgia Bureau of Investigation looked into the conduct of Garland, the spokesperson for Mayor Reed, in handling ORA requests and ultimately pressed charges. Garland was convicted on two misdemeanor charges of deliberately frustrating requests for public records. She was fined $\$ 1,980$ but received no probation or jail time.

The punishment was meager, but the conviction noteworthy in the field of freedom of information (FOI) laws. It marked not only the first conviction, but also the first criminal investigation under the ORA, which was amended in 2012 to make violations criminal. The case received national coverage, with The New York Times observing the noteworthy outcome: "It is a rare predicament for an American government official," as Garland was, to be charged with intentionally obstructing access, calling the charges "extremely uncommon" in the United States (Fausset, 2019). Penalty provisions are so rarely applied that in Colorado's 2017 amendment of its state Open Records Act (CORA), legislators excised a misdemeanor penalty for the willful and knowing violation of CORA. The executive director of the Colorado Freedom of Information Coalition said the organization had no recollection of anyone ever being prosecuted for the crime, which carried a penalty of up to 90 days in jail and a \$100 fine (Roberts, 2017).

Garland's instruction to "be as unhelpful as possible" provides a window into the oftenhostile confrontations between FOI requesters and public bodies. The nature of the contentious legal mechanism introduces many issues, most of which can be categorized as either inherent frictions or deliberate frustrations. Inherent frictions can occur around disputed statutory language, the classification of a record, redaction choices, and processing delays. These are good-faith interpretive issues or real workload constraints. Garland's desire to intentionally slow processes, produce records in problematic formats, and generally exasperate the requesters would qualify as deliberate frustrations.

There are countless other methods for unnecessarily introducing aggravation into the FOI request process, including exorbitant fees, misapplied exemptions, and inapt denials. Each of these deliberate frustrations is rooted in the existence of an inherent friction. Thus, it is public officials exploiting the existing tensions of the law to undermine its intended objectives. An important course of action in improving public records laws involves mitigating inherent frictions and eliminating deliberate frustrations. Identifying and addressing legal frictions and frustrations could provide valuable grist in amending and enforcing FOI laws. 
A substantial body of research explores political and legal variables, as well as public opinion on FOI preferences and results (Spac et al., 2017; Piotrowski \& Van Ryzin, 2007). This study examines legal variables in state FOI laws via an exploratory study. Before investigating the varied characteristics of state public records laws, the article will consider theories and rationales for the mounting complications in implementing FOI laws. Then, the article will produce a statistical analysis of 1,002 public records requests submitted across nine states in an effort to isolate legal issues correlated with FOI compliance. The FOI audit requested noncontroversial, readily accessible records, and thus evaluates how government bodies across the country comply with simple requests. The article explores not disputed elements of the law but seeks to identify specific legal characteristics that either benefit or impede common FOI processes and outcomes.

\section{Burdening the FOI process}

Garland faced charges in Georgia over violations of the ORA, specifically for violating a provision that forbade "knowingly and willingly frustrating... the access to records by intentionally making records difficult to obtain or review" (Georgia Open Records Act, 2020). The provisions were new to the Georgia law and intended to discourage behavior like Garland's. On its codification, the Georgia attorney general praised the 2012 ORA amendments, calling them "the teeth needed to enforce the law" (Georgia Department of Law, 2012). Garland had conspired to make the ORA request difficult, to frustrate the requester and to undermine the function of the law. The Georgia legislature and attorney general sought to root out just these kinds of deliberate frustrations.

Herd and Moynihan (2018) have defined these kinds of intentional obstructions as administrative burdens, where "political ideology or policy preferences lead politicians to use burdens to make government a source of hinderance rather than of help" (p. 14). When a law is enacted, there is an assumption of good-faith implementation on the government's part, and often behavioral economics assumes burdens are incidental and not intentional, but the concept of administrative burden flips that assumption, suggesting long-term, unaddressed administrative issues are likely intended to undermine the law. Unworkable policy is not happenstance or an intrinsic byproduct of complex implementation; such sustained policy problems are presumed to be deliberate. While Herd and Moynihan are more focused on legal design that builds in difficulty or frustration, the concept also has downstream effects where enactment is slipshod, and oversight largely abandoned.

A premise of the administrative burden concept is in allowing the government to present and publicize the benefits of a government policy and accept any accordant goodwill, while minimizing government responsibility through bureaucratic and clerical hurdles. This allows the government to, as the adage goes, "have its cake and eat it too." Politicians receive the accolades for the manifestation of the program, while using a fraction of the assets and resources. Criticism is dismissed as a failure in lower-level administration or blamed on witless citizens. There are myriad reasons public officials may seek to introduce or allow administrative burdens, many of them political. FOI laws give public officials considerable incentive to deliberately frustrate requesters; most notably the ability to conceal embarrassing or incriminating information. Scholars have found FOI laws to be subject to administrative burdens (Bashir \& Nisar, 2020; Michener et al., 2020). Worthy (2017) has suggested politicians grow to resent transparency and its accordant potential for exposure and uncertainty. Worthy observed that embracing transparency entailed ceding some of a politician's hard-won power, often to political opposition: "Opening up equates to a loss of control and a potential empowerment of enemies and critics. So once in office, actors seek to stall, delay and water down commitments: the classic trajectory of FOI reform is one of survival through dilution" 
(p. 2). Former U.K. Prime Minister Tony Blair, under whom the nation adopted its first FOI law, was explicit in his regrets. In his memoirs, he called his support for the law "naïve, foolish, irresponsible... I quake at the imbecility of it" (Blair, 2010, p. 466). In criticizing FOI laws, Blair was unusually candid for a public official, suggesting the laws are merely a weapon of the press and political opponents, and the limited view afforded by FOI only further confused the public.

Due to the symbolic prominence of transparency laws, politicians cannot merely sweep them away. They must unobtrusively subvert the law, to hobble its impact while allowing the symbolic banner of transparency to remain. Undermining FOI quietly wrests back some of the power, and the more granular act of frustrating public records requests serves two more immediate purposes. When a public body delays a request, it makes the information less valuable (especially for deadlinedependent journalists). In providing a denial or a hard-to-decipher response larded with legalese, not only does the public body retain its secrecy (and potentially withhold embarrassing or incriminating records), it discourages future requests. It signals to the requester that this information is not for them, or they will need to mount a sustained effort to receive it. FOI laws manifest administrative burdens through varying provisions and legal elements and a general failure in oversight and enforcement. Administration of the law has become disfigured in courtrooms and capitols across the country. The laws are intended to be simple, but a bevy of administrative burdens belabor the process.

\section{Characteristics of FOI laws}

Along with the federal Freedom of Information Act (FOIA), all 50 states and Washington, D.C., have public record laws, and these laws vary in significant ways. This article seeks to highlight the most salient of these disparities in understanding how different statutory manifestations are related or unrelated to FOI outcomes and processes, while considering how these legal elements are also hosts to inherent frictions and deliberate frustrations.

\section{Subject bodies}

In his recommendations for universal FOI standards, Toby Mendel (2003) called for broad application of the laws as a foundational step. While Mendel sought specific affirmative disclosure expectations from as a wide a range of public bodies as possible, the scope of FOI laws, and government transparency generally, is explicitly determined by the legislature's (or in rare cases, the court's) decision as to which bodies will be subject to FOI expectations. FOI laws are almost universally targeted at executive or administrative elements of government, and U.S. state FOI laws all make the executive branch subject to requests. Some FOI laws exclude the head of the executive branch, including the state governor's office, under the premise of executive or presidential privilege. Unlike the federal FOIA, some states extend the reach of their FOI law into the legislative and judicial branches, though many state legislatures have chosen not to include themselves, and in some instances, courts have determined they are not subject as well.

\section{Deadlines}

Journalists, legislators, and scholars have routinely identified delay as the No. 1 issue with public records laws (Grabell, 2016; Committee on Oversight and Government Reform, 2016; Hazell and Worthy, 2010). Statutory deadlines are intended to mitigate slow responses and control delay in processing FOI requests. Yet, a review of federal FOIA lawsuits since 1992 found "failure to respond within statutory time limit" to be the most common legal complaint (The FOIA Project, 2020). States 
have diverse approaches to statutory deadlines with some providing no mention of deadlines, others only an ambiguous expectation of expediency, while others have codified relatively quick turnaround requirements. Cuillier (2019) suggested there is an assumption that explicit deadlines produce the best results, but his research found deadlines to have no significant effect on FOI processes.

\section{State offices of oversight}

Another area of scholarly interest has been state-run oversight offices (Fenster, 2015; Danielson, 2012; Stewart, 2010). These bureaus are most commonly focused on open government compliance, primarily via mediation and enforcement. As with other elements of FOI laws, the structure and authority of the offices varies state-by-state. In most states, these offices were created after initial enactment, signifying an effort to reform FOI operations and establish stricter adherence. Other motives for establishing oversight offices include interest in cutting costs by avoiding expensive litigation that crowded court dockets and, in New Jersey's case, a direct response to a rash of public corruption (Stewart, 2010). The offices typically carry out specific duties or responsibilities; namely educating and guiding requesters and public bodies, mediating disputes between requesters and public bodies, and involvement in litigation.

There are a number of important factors when considering the effectiveness of these oversight offices. Danielson (2010) suggested the most common characteristic of successful oversight offices was independence, finding bureaus affiliated with the state attorney general to be "almost uniformly ineffective, because attorneys general have insufficient time, interest, or resources to prosecute open records requests" (p. 1,018). State departments of justice are inherently political, leaving them prone to conflicts of interest and political manipulation; making them poor choices for resolving transparency disputes. Fenster (2015) highlighted two other critical elements; the ability to investigate disputes and binding authority to enforce decisions. Investigation of requester grievances is key, because without the legal authority to compel public bodies to cooperate, public bodies can make light of or stonewall oversight efforts. Some states have given these offices the ability to subpoena information relevant to an investigation. Of equal importance, binding authority to enforce decisions is a common but nonuniform element of oversight offices. Without binding authority, these offices have little more than moral authority to resolve disagreements. Often, these offices will produce public opinions, which courts may consider, but these opinions have no definite legal influence, are easy to disregard and ultimately do little more than state a position for the general public to contemplate.

\section{Independent advocacy organizations}

Mendel's second, and less intuitive, recommendation for universal FOI standards was active promotion of open government, including public education and training of officials. In many states, this role has been filled by nongovernment entities. For instance, the Washington Coalition for Open Government plays an official role in training records custodians. While FOI advocacy organizations adapt to fit the needs of the state, it has become clear they play a key role in the legal ecosystem and the realization of FOI laws. These FOI-focused organizations concentrate solely on the functions of educating, overseeing, and litigating state public records and open meetings laws. They act as a citizen-centric corollary to the state oversight offices.

The composition, resources, and activity of these advocacy organizations vary, but in most cases they serve as a primary FOI resource for the public, acting as a knowledge base both holding training and information sessions and responding to everyday questions from requesters. Often, they 
provide templates and tips for requesters that demystify the legal process. A key responsibility of FOI advocacy organizations is their role as a non-state legal authority. In this position, they often operate a hotline connecting requesters with lawyers or FOI experts, both aiding the requesting process and keeping a finger on the pulse for potential issues. Perhaps the most important element of the advocacy organization's function is its ability to litigate or support litigation of cases. Some organizations offer full legal representation for select cases, while others may connect a requester with a lawyer (who may work contingent on being awarded attorneys' fees, which are recoupable for successful suits in many states).

\section{Exemptions}

When considering research and press coverage, study of legal exceptions or exemptions would rank among the most popular. The federal FOIA provides nine explicit exemptions, and for the most part states have adopted a similar approach to exemptions. The most common and clearly articulated exemptions exclude release of records pertaining to personal privacy and law enforcement. All states also include a statutory exemption, which excludes records required to be withheld by other statutes. Often these statutory exemptions are codified as a small provision of sizeable, otherwise unrelated legislation, and over time these exemptions have accumulated with little accountability. Despite all states using a similar exemption template and same foundational exemptions, it should be noted that exemption schemes vary dramatically according to state character and legislative interests.

\section{Fees}

Copy and search fees are another area of concern among requesters and scholars alike, and examples of exorbitant fees surface with regularity (Wilks, 2020; Dolan, 2018; Thompson, 2017). These high fee estimates are often used as administrative burdens. Records custodians seek to dissuade requesters by requiring excessive fees for requested records. Lotte Feinberg (1986) has documented the practice as far back as the Reagan administration, and the tactic has been publicly acknowledged at the federal level as recently as the Obama administration (Jones, 2015). Governments have attempted to combat fees as barriers through restrictions on fees, and this has primarily been accomplished through two approaches. Some states provide loose or ambiguous limits on the amount that a requester can be charged, using language like "reasonable" or limiting fees to the "actual cost" of search, review, and duplication. Others enforce explicit cost restrictions, providing a fee schedule that, for instance, charges 25 cents for a standard one-sided copy.

\section{Penalties}

FOI penalties are the teeth of Georgia's ORA and many other FOI laws and are meant to discourage and punish deliberate frustrations. In his study of state FOI laws, Marzen (2018) concluded that enhanced penalties and legal consequences were crucial to the function and improvement of FOI laws. Penalties can be realized in a wide variety of manners, including civil and criminal remedies and can range from small civil fines, like Garland received in Atlanta, to jail time and compulsory removal from custodian's duties. In many states, public bodies can be required to pay the plaintiff's attorney fees. There are articulations within each of these penalties, particularly in whether the penalties are optional or mandatory, turning on the statutory word choice of "may" or "shall." The detail and experimentation in different forms of penalties represent governments' 
sustained interest in enforcing compliance. Yet, there is no single accepted approach to punishing flagrant violators of FOI laws. Stewart (2010) has suggested no matter the statutory or common law manifestations of penalties, a more consistent approach is necessary for these provisions to yield their intended outcomes.

The objective of this study is to further explore which of these legal characteristics influence FOI results. The following exploratory research questions were asked in an effort at extending and establishing a firmer understanding of the legal characteristics related to state FOI outcomes and processes:

$R Q 1:$ How are legal variables related to compliance with public records requests?

$R Q 2:$ How are legal variables related to records request completion times?

$R Q 3:$ How are legal variables related to how quickly and completely agencies communicate with requesters?

\section{Methods}

The article sought to consider the fundamental operations of nine FOI systems through an exploratory field study employing 1,002 actual public records requests. The primary objective of the project was to determine whether FOI laws work for everyday citizens and journalists, and then considering which, if any, legal factors are correlated with desirable outcomes. In an effort to test the basic premises of these laws, the study requested simple, noncontroversial records, submitted requests exclusively to county-level government agencies, and considered quantifiable results, such as outcome, completion time, and how and when agencies communicated with requesters.

\section{The requests}

The study is an exploratory field survey — or FOI audit—of nine U.S. states, comprising 1,002 requests across 334 counties, employing techniques similar to previous FOI request-based field studies (Ben-Aaron et al., 2017; Cuillier, 2010; Grimmelikhuijsen et al., 2018; Jenkins et al., 2020; Spac et al., 2018; Worthy et al., 2017). The study was conducted during two time periods: Feb. 11, 2019, to July 10, 2019, and June 3, 2019, to Dec. 4, 2019. The majority of the requests, 786, were submitted by the author and four research assistants starting June 3, 2019. The remaining 216 requests were submitted on Feb. 11 by students in a graduate course. In both batches, the requesting process was tightly controlled. All requests were submitted as emails from a Gmail account clearly affiliated with the author. The subject line of each email identified the message as a request per the state FOI law. The body included a similar message with a reference to the appropriate statutory code and directed the email recipient to the request, an attached PDF. The request acknowledged the law and statutory code and clearly stated the sought records; a preferred file format (PDF) and delivery method (email) were indicated. The request provided the identity and profession of the requester, a general purpose for the requested information, and asked the recipient to identify any justifications for denial or delay. In jurisdictions with a statutory deadline, the request asked that the body meet the deadline. In cases where the public body provided no acknowledgement of receipt, evidence of progress or an estimated date of delivery, follow-up emails and phone calls occurred at coordinated intervals.

The requested records varied but were intended to be relatively routine and require a minimal amount of time to complete. In all cases, the requested records were substantial and meaningful but unequivocally free of exemptions or legal dispute. The objective in determining what records to request was in duplicating a basic request that was easy for public body to search, review, and deliver. 
Three public records requests were submitted to all 334 counties. In total, five different records requests were used due to differing government structures and responsibilities. In all 334 counties, a request was submitted to the county sheriff's office seeking incident reports for a two-day period. In seven states, excluding Oklahoma and Maine, a request for complaints about potholes was submitted to the county office responsible for roads maintenance. In Oklahoma, where there is no stand-alone county-level roads department, the pothole request was submitted to county commissioners. In Maine, a request was submitted to the county Emergency Management Agency for the county's hazard mitigation plan, a state statutory requirement. In all states except Wisconsin, a request for recent collective bargaining agreements was submitted to the highest-ranking official, body, or records clerk in the county. In Wisconsin, a request was submitted to each county's district attorney for the office's annual budget.

Sample

The project chose to make requests to county-level offices and departments in an effort to consider an expansive, diverse, and stable range of governments. Counties are relatively consistent across the country, performing common functions across many states. They conduct routine law enforcement, road maintenance, and administrative functions in all corners of the United States. A primary motivation for choosing county and not municipal entities is the stability, which allows the project to consider more rural populations and ultimately a broader sample of American law. Municipal governments, especially in less populous locales, demonstrate broad variance in solidity and reliability. County governments often respond to state mandates in a way that municipal governments often do not and with these responsibilities comes stability and resources.

Nine states were identified for their geographical diversity, variance in key FOI law characteristics, and open government reputations. The study was especially interested in statutory deadlines, penalty provisions, fee provisions, and oversight offices; as such, the sample states represent differing approaches to these legal variables. The article also accounted for public perceptions of each state's FOI law effectiveness in determining the state law sample (Cuillier, 2019; Qiu et al., 2015). With regard to geography, the U.S. Census Bureau divides the nation into four regions and subdivides the four regions into nine divisions. In all, each region is represented with at least two states and each division with one state. In Maine, New Jersey, Washington, Wisconsin, and Wyoming, requests were submitted to all counties. In Florida, Iowa, Mississippi, and Oklahoma, the counties were divided in half and sorted by total population, and a request was submitted to every other county starting with the most populous.

\section{Variables}

The project compiled a wide range of data on the FOI request process - fees required, fees threatened, format choice, method of communication (email, fax, or postal mail), a subjective rating of compliance and hostility_-but ultimately focused on the following variables, for simplicity.

\section{Predictor variables}

The following predictor variables comprising legal factors were created for each state, based on evaluation of state laws, previous studies, and other resources. These variables would then, through statistical analysis, be compared to the criterion outcome variables derived from the FOI audit. Scholars have warned against transparency formalism, or analyzing the letter of the statutes 
(Pozen, 2020), and the project has instead examined the law as applied, or de facto. To that end, the study consulted not only state codes but court cases, attorney general and enforcement office opinions, and the Reporter's Committee for Freedom of the Press Open Government Guide. Once each state law was coded, an expert on each state's FOI law reviewed the results. The variables represent notable characteristics of FOI laws. Some have long been debated, while others represent more novel legal considerations.

Subject bodies. All FOI laws include the executive branch, and all nine sample states include the governor's office, leaving the study to consider the legislative and judicial branches. Each was considered separately, and state laws that did not subject the legislature or the judiciary were coded as 0 , and when the state law expected the legislature or the judiciary to comply with FOI requests a 1 was recorded. In some states, broad exemptions for either the legislature or the judiciary severely limit access to records among these institutions. In these instances, the branches were still considered subject to the FOI law. If a request produced an FOI response, even if citing a broad exemption, the body was considered subject.

Deadlines. The deadlines were drawn from the state statutes. Unless there was a controlling judicial interpretation, the number of days identified in the black letter of the law was used as a continuous variable for all counties in each state. In analysis, states with ambiguous deadlines (e.g., "reasonably prompt") were determined to not have statutory deadlines.

State oversight offices. The state oversight offices considered three factors before reducing the variable to a binary. Those that had oversight, ombuds, or enforcement offices independent of the attorney general, with investigative powers and binding authority to enforce a decision, were coded as a 1. Those states that had no oversight office or an office with two or less of independence, investigative powers and binding authority were coded a 0.

Independent advocacy organizations. For the purposes of the study, states were coded as either a 0 for no state advocacy organization or a 1 for a state law with an advocacy organization. To qualify as an advocacy organization, the organization must be active, have a clear and recognizable identity and be solely dedicated to state open government causes. This precludes state press organizations, which frequently do valuable work in advocating for open government but concern themselves with a range of legal issues in addition to open government.

Exemptions. Exemptions were recorded as a continuous variable. The study used the number of explicit exemptions defined in the state's FOI statute and did not account for statutory exemptions elsewhere in state codes. The counts ranged from eight for Wisconsin (a state relatively reliant on common law exemptions) to 73 for Iowa. It is important to note that in many cases, the state experts disagreed with the recorded number; observing there were hundreds of unaccounted for statutory exemptions. The study used explicit and defined exemptions in statute as an indicator of legislative intent in detailing and updating records categories to be excluded. The profound difficulty in determining an exact number of total exemptions with statutory exemptions proved prohibitive as well, as many states do not keep an official calculation.

Fees. The study borrowed Cuillier's (2019) “copy fees" variable, relying on a 0-2 scale. States that made no mention or provided no guidance regarding fees were scored a 0. State laws that provided an ambiguous fee schedule or expectation (e.g., "reasonable costs" or "actual costs") were recorded as a 1. State laws that provided a specific fee schedule (e.g., a maximum of 25 cents per page) were recorded as a 2 .

Penalties. All states have penalties provisions in their statutes. The baseline for penalties is a one-time fine for a violation of the FOI law. Other states have provisions opening up the possibility of more severe penalties, including felonies that include jail time. The study has used a binary code, recording a 0 for state FOI laws whose statute proposes only a one-time fine and a 1 for state FOI 
laws that have more severe penalties, such as escalating fines or the possibility of jail time. See Table 1 , below, for descriptive statistics of the predictor variables.

\section{Table 1}

Descriptive Statistics for Predictor (Legal) Variables

\begin{tabular}{llll}
\hline Variable & Mean & SD & $N$ \\
\hline Leg. Subject & .736 & .441 & 1,002 \\
Jud. Subject & .704 & .457 & 1,002 \\
Deadline & .500 & .500 & 1,002 \\
Oversight Office & .548 & .498 & 1,002 \\
Advocacy Org. & .808 & .394 & 1,002 \\
\# of Exemptions & 32.36 & 18.817 & 1,002 \\
Fee Schedule & 1.380 & .486 & 1,002 \\
Penalties & .520 & .500 & 1,002 \\
\hline
\end{tabular}

\section{Criterion variables}

The criterion outcome variables were derived from measuring the performance of the agencies through the 1,002 public records requests. These outcome variables would then be compared to the predictor variables to see what legal factors are related to more desirable outcomes.

Outcome. The first main criterion variable focuses on the actual results of the requests - did the requester get what was requested? The study coded the 1,002 requests into one of three categorial outcome variables. A Positive Outcome connoted a request that was completed successfully, either the requested records being transferred to the requester or the public body informing the requester of the existing availability of the information online. A Neutral Outcome represents requests that concluded with a No Records response, where the public body informed the requester that the requested records did not exist. The third result was a Negative Outcome and indicates a failed request, where the agency either denied the request or the request was abandoned due to the bodies' sustained unwillingness to communicate or refusal to mail, email, or fax the records.

Time. The article considered both the amount of time to receive a first response from an office or department, as well as the amount of time to complete the request. The two continuous Time variables used were Days until Completed and Days until First Response. Both represent a count of the total number of days from request submission. Days until Completed counts the number of days from request submission to the date the records were received, the requester was informed of the records existing online publication, the requester was informed of No Records response, the request was denied or the request was recorded as failed. Days until First Response counts the number of 
days from request submission to the date the public body first acknowledged receipt of the request. The $N$ for Days until Completed is 981 due to 21 requests never reaching completion.

Communication. The study also analyzed the number of ignored communications (either an email or a phone message) and the number of additional follow-up communications needed to complete the request. No Response is a count of the number of times communication was attempted until the public body acknowledged receipt of the request. Additional Contacts is a count variable recording the number of additional communications needed beyond the initial submission (the original submission is not counted in this number).

For examples, a request for pothole complaints was submitted to the county commissioner's office in Pontotoc County, Oklahoma, on June 3, 2019. The office did not respond to the first three efforts at submitting the request (two emails and one phone call). Forty-three days elapsed before the county acknowledged receipt of the request. The request required an additional four follow-up communications to complete the request. Before they could be released, the county board of commissioners scheduled and discussed the request at a meeting, and a total of 78 days passed between initial request and the delivery of three small digital files of unredacted pothole complaints. The request was recorded as a Positive Outcome, 43 Days until First Response, 78 Days until Completion, 3 No Responses and 6 Additional Contacts. Descriptive statistics are in Table 2.

Table 2

Criterion (Outcome) Descriptives by State

\begin{tabular}{|c|c|c|c|c|c|c|c|c|}
\hline \multirow[b]{2}{*}{ State } & \multirow[b]{2}{*}{$N$} & \multicolumn{3}{|c|}{ Outcome } & \multicolumn{2}{|c|}{ Time } & \multicolumn{2}{|c|}{ Communication } \\
\hline & & $\%$ Pos. & $\%$ Neu. & $\%$ Neg. & $\begin{array}{l}\text { Avg. Days } \\
\text { Comp. }\end{array}$ & $\begin{array}{l}\text { Avg. Days } \\
1 \text { Resp. }\end{array}$ & $\begin{array}{l}\text { Avg. \# No } \\
\text { Resp. }\end{array}$ & Avg. \# Add. Cont. \\
\hline Florida & 102 & 70 & 30 & 0 & 18 & 6 & .28 & .66 \\
\hline Iowa & 147 & 65 & 35 & 0 & 16 & 12 & .51 & .61 \\
\hline Maine & 48 & 73 & 21 & 6 & 9 & 4 & .15 & .35 \\
\hline Mississippi & 123 & 37 & 55 & 8 & 28 & 22 & 1.35 & 1.91 \\
\hline New Jersey & 63 & 73 & 27 & 0 & 16 & 10 & .35 & .57 \\
\hline Oklahoma & 117 & 23 & 68 & 10 & 22 & 19 & 1.04 & 1.71 \\
\hline Washington & 117 & 92 & 9 & 0 & 13 & 4 & .10 & .30 \\
\hline Wisconsin & 216 & 81 & 19 & 0 & 14 & 9 & .32 & .52 \\
\hline Wyoming & 69 & 45 & 51 & 4 & 15 & 10 & .42 & .61 \\
\hline All & 1,002 & 63 & 34 & 3 & 17 & 11 & .53 & .84 \\
\hline
\end{tabular}


Analysis

The data were analyzed using multiple logistic regression (Outcome), negative binomial regression (Time; Days until Completion, Days until First Response) and Poisson regression (Communication; No Response, Additional Contacts) to assess the relationship between the variables. As the only nominal variable, Outcome was assessed using multiple logistic regression, as the variable was categorized into three groups (Positive, Neutral, and Negative), and Neutral Outcome was used as the reference variable. And while OLS regression was an option, the Outcome variables are not truly ordinal. The Time and Communication variables were counts data measured in discrete units, and normal distribution of residuals could not be assumed. With Time and Communication variables, the lowest count was zero, and the nature of the variables left error distribution skewed to the right. The Time variables had a larger mean and demonstrated overdispersion, and negative binomial regression was determined to be the most appropriate estimation method. Poisson regression was used for Communication variables as there were no dispersion issues.

\section{Results}

In considering $R Q 1$, how legal variables are related to public records request outcomes, four predictors had significant parameter estimates when comparing the Positive Outcome with the Neutral Outcome, and two predictors have significant parameters when comparing the Negative Outcome with the Neutral Outcome (see Table 3 and Table 4, below).

The presence of active advocacy organizations was the only predictor with significant parameters for both Positive and Negative Outcomes. Advocacy organizations predicted a strong likelihood that requests would be granted or proactively disclosed rather than receive a Neutral Outcome. Advocacy organizations also strongly predicted a decreased likelihood of denial or failed request rather than receive a Neutral Outcome. Three other legal variables - the legislature being subject to the FOI law; an independent, empowered state oversight office; and an established fee schedule - also were significant predictors of a Positive Outcome rather than a Neutral Outcome. Legislatures being subject to FOI law was found to be the strongest predictor of a Positive Outcome.

\section{Table 3}

Predictors' Unique Contributions in the Multinomial Logistic Regression $(N=1,002)$

\begin{tabular}{lrll}
\hline Predictor & $x^{2}$ & $d f$ & $p$ \\
\hline Leg. Subject & 80.843 & 2 & $.000^{* * *}$ \\
Jud. Subject & 1.804 & 2 & .389 \\
Oversight Office & 9.882 & 2 & $.007 * *$ \\
Advocacy Org. & 129.82 & 2 & $.000^{* * *}$ \\
$\#$ of Exemptions & 1.804 & 2 & .406 \\
Fee Schedule & 22.856 & 2 & $.000 * * *$ \\
\hline
\end{tabular}

Note: $\chi^{2}=$ amount by which -2 log likelihood increases when predictor is removed from the full model.

$* p<.05, * * p<.01, * * * p<.001$ 


\section{Table 4}

Results of Multinomial Logistic Regression Contrasting the Neutral Group versus Positive and Negative Groups $(N=1,002)$

\begin{tabular}{lcccc}
\hline Predictor & Neutral vs. & \multicolumn{1}{c}{ OR } & $p$ \\
\hline Leg. Subject & Positive & 2.044 & 7.723 & $.000^{* * *}$ \\
& Negative & -1.049 & .350 & .322 \\
Jud. Subject & Positive & .360 & 1.434 & .179 \\
& Negative & -.411 & .663 & .203 \\
Oversight Office & Positive & .515 & 1.674 & $.003^{* *}$ \\
& Negative & -.581 & .559 & .547 \\
Advocacy Org. & Positive & 1.878 & 6.538 & $.000^{* * *}$ \\
& Negative & -1.865 & .155 & $.008^{* *}$ \\
\# of Exemptions & Positive & .001 & 1.001 & .875 \\
& Negative & -.035 & .965 & .203 \\
Fee Schedule & Positive & 1.236 & 3.443 & $.000^{* * *}$ \\
& Negative & -.838 & .433 & .552 \\
\hline
\end{tabular}

Note: $O R=$ odds ratio associated with the effect of a one standard deviation increase in the predictor.

$* p<.05, * * p<.01, * * * p<.001$

Table 5, below, provides the results for $R Q 2$, how legal variables are related to response and completion times. The results for the negative binomial regression for Days until Completed identified four variables as significant in predicting the number of days a request would take to be completed. Three of the significant predictors - explicit fee schedule, subject legislature, and advocacy organization-were found to predict faster completion times. The number of explicit statutory exemptions were found to predict a small but significant increase in the number of days until the request is completed. Three of the same predictors - explicit fee schedule, subject legislature and advocacy organization-were also found to be significant in predicting how quickly a department or office would first respond to or acknowledge receipt of the request. 


\section{Table 5}

Results of Negative Binomial Regressions ( $N=981,1,002)$

\begin{tabular}{|c|c|c|c|c|c|c|}
\hline \multirow[b]{2}{*}{ Variable } & \multicolumn{3}{|c|}{$\begin{array}{l}\text { Days until } \\
\text { Completed }\end{array}$} & \multicolumn{3}{|c|}{$\begin{array}{l}\text { Days until First } \\
\text { Response }\end{array}$} \\
\hline & $\beta$ & $B(S E)$ & $p$ & $\beta$ & $B(S E)$ & $p$ \\
\hline \multicolumn{7}{|l|}{ Subject Bodies } \\
\hline Leg. & -.383 & .135 & $.004 * *$ & -1.136 & .137 & $.000 * * *$ \\
\hline Jud. & .017 & .144 & .904 & -.216 & .147 & .142 \\
\hline Deadline & -.105 & .112 & .378 & -.004 & .121 & .975 \\
\hline Oversight Office & -.154 & .096 & .106 & .026 & .098 & .009 \\
\hline Advocacy Org. & -.375 & .100 & $.000 * * *$ & -.907 & 1.020 & $.000 * * *$ \\
\hline \# of Exemptions & .008 & .004 & $.035 *$ & .000 & .039 & .975 \\
\hline Fee Schedule & -.640 & .139 & $.000 * * *$ & -.716 & .143 & $.000 * * *$ \\
\hline Penalties & .209 & .127 & .100 & .105 & .135 & .435 \\
\hline Likelihood ratio $\mathrm{x}^{2}$ & $71.859 * * *$ & & & $254.600^{\prime}$ & & \\
\hline
\end{tabular}

Note: The $N$ for Days until Completed is 981 due to twenty-one requests never being completed and being recorded as failed.

$* p<.05, * * p<.01, * * * p<.001$

The results for the statistical analysis addressing $R Q 3$ can be found in Table 6. The final research question considers communication factors of the requesting process: number of no responses, or the number of times the initial request was ignored, and number of additional contacts, or the number of times communication beyond initial submission was required to complete (or fail) the request. As is to be expected due to the correlative nature of the Time and Communication variables, the results of the Poisson regression are very similar to the negative binomial regression addressing the Time variables. States with advocacy organizations and laws that include the legislature in the FOI and include a reasonable fee schedule were found to be strong predictors in decreasing the number of times a request was ignored or not responded to. The same three variables were also the strongest predictors of additional contacts or communications. Each of advocacy organizations, subject legislatures and explicit fee schedules were found to be significant in predicting a decrease in the number of communications needed to close a request. The presence of a statutory deadline and a strong, state oversight office also predicted moderate decreases in the number of additional contacts. 


\section{Table 6}

Results of Poisson Regressions $(N=1,002)$

\begin{tabular}{|c|c|c|c|c|c|c|}
\hline \multirow{2}{*}{ Variable } & \multicolumn{3}{|c|}{ No Response } & \multicolumn{3}{|c|}{$\begin{array}{l}\text { Additional } \\
\text { Contacts }\end{array}$} \\
\hline & $\beta$ & $B(S E)$ & $p$ & $\beta$ & $B(S E)$ & $p$ \\
\hline \multicolumn{7}{|l|}{ Subject Bodies } \\
\hline Leg. & -1.185 & .237 & $.000 * *$ & -.851 & .158 & $.000 * * *$ \\
\hline Jud. & .112 & .255 & .660 & .219 & .186 & .238 \\
\hline Deadline & -.119 & .218 & .585 & -.388 & .153 & $.011 *$ \\
\hline Oversight Office & .188 & .186 & .312 & -.318 & .127 & $.012 *$ \\
\hline Advocacy Org. & -1.446 & .195 & $.000 * * *$ & -1.022 & .132 & $.000 * * *$ \\
\hline \# of Exemptions & -.005 & .009 & .545 & -.005 & .006 & .388 \\
\hline Fee Schedule & -.778 & .279 & $.005^{* *}$ & -.883 & .191 & $.000 * * *$ \\
\hline Penalties & .248 & .330 & .456 & -.073 & .206 & .724 \\
\hline Likelihood ratio $\mathrm{x}^{2}$ & $274.562 * * *$ & & & $331.024 *$ & & \\
\hline
\end{tabular}

$* p<.05, * * p<.01, * * * p<.001$

\section{Discussion}

The findings suggest, among the legal variables in the study, three are closely correlated with better FOI outcomes and processes: 1) a legislature subject to the FOI law, 2) an independent state FOI advocacy group and 3) defined fee limits.

The legislature being subject to the state FOI law can be read as a signal of sincerity and interest in pursuing thorough-going transparency. In most cases, the legislature has amended the statute, opting themselves into FOI responsibility. Schudson (2015) has documented the mid-20th century advent of modern FOI laws, suggesting in the United States the legislative movement was more of a congressional power grab than a democratic project. And as a result, Congress left itself out of the law and aimed the mechanism at the executive branch. In this light, legislatures that have opted in can be viewed as more invested in public interest transparency. This is a government body choosing inconvenience for the sake of access to government information. Certainly, some legislatures have also passed exemptions severely limiting the range of legislative records available, but the fundamental act of the body choosing to include itself in FOI responsibilities suggests a state 
committed to FOI beyond mere tokenism. FOI laws, at the federal, state, and local levels, often must compete for resources, and custodians are often short-staffed and requests can be backlogged due to personnel limitations (AbouAssi \& Nabatchi, 2018). Where some states allow FOI offices and custodians to languish, these are states that have expanded their commitment to FOI and moved more resources to support the cause. The uniformity and the strength of the findings was also notable. Having a legislature subject to FOI laws predicted more positive outcomes, faster response, and completion times, fewer ignored requests and fewer communications to complete the request; all these findings were among the strongest significant predictors in the study.

Along with legislatures subject to FOI laws, the presence of independent advocacy organizations predicted equally as strong of findings; More positive outcomes, fewer negative outcomes, quicker responses and completion, ignored less frequently and required fewer additional contacts. Like subject legislatures, this is not necessarily an obvious or intuitive finding. There is certainly a logic to it, though. Worthy (2017) has called these coalitions proxy forces that supply the momentum to push forward FOI laws and amendments in the absence of government support. They often represent an organized bottom-up force in realizing FOI laws. While states have attempted to implement their own oversight offices, it appears they are too close to the politics and too volatile in leadership to realize thorough and consistent oversight. By contrast, independent advocacy organizations make compliance their primary purpose and are able to do so divorced from government machinations. The findings suggest this true independence to be a key, as some states appear to have made sincere efforts to insulate state oversight offices. Another valuable facet of advocacy organizations is their flexibility. They address issues as they surface, which is critical in any legal expectation, especially so when compliance is often seen as a galling obligation. New FOI loopholes materialize and proliferate with some regularity. The responsiveness of these organizations allows them to remain current and adapt as needed. Legislatures nor courts can anticipate efforts to circumvent the laws. The focus and proximity of advocacy organizations allows them to remain vigilant and alert to state and local concerns. This is encouraging news for states interested in better FOI compliance. Investing more resources in these organizations and encouraging these organizations to increase activity across the board - education, training, answering requester queries, and litigating — would likely lead to better FOI compliance and results.

The third of the three strong predictors, explicit fee schedules, has a fairly apparent logic to it. Fee schedules are a more granular finding than subject legislatures or advocacy organizations, and the strength and significance of its value as a predictor was also weaker. However, states that have codified clear limitations to the fees that requesters can be charged likely suggests evolution in the statute and sustained legislative effort in improving the law. While many of the statues use the language of the pre-digital era (most often prescribing costs for different copy sizes), they eliminate wildly exorbitant fees (though abuse can still occur). State laws that rely on ambiguous language like "reasonable" allow public bodies a good deal of latitude and can result in the common FOI charade of stonewalling a requester with a suggestion that they litigate if they disagree with the assigned fee. The explicit fee schedule is the most technical of the three major significant legal variables, but it also accords with a theme. Subject legislatures, advocacy organizations and fee schedules are all read as fairly clear efforts to improve FOI results.

That penalties were found to be insignificant, as well as the general paucity of significant legal variables generally, is an interesting finding. Penalties are so rarely applied as to make national headlines when a mayor's chief of staff is fined $\$ 2,000$ for flagrantly violating the law. So, while the study attempts to consider the impact of different penalty provisions, these penalty provisions, no matter their severity, are invisible in the everyday function of the laws. And this same principle can be applied to many of the legal variables. It is difficult to measure relationships when implementation 
of the legal variables is inconsistent. The variable may be accurate de jure, but these penalty provisions are not present de facto, and as a result the penalty provision having no statistical significance feels curiously accurate. Instead, the study found significant predictors in variables that signal a culture of compliance. Legislatures being subject to the law and independent advocacy organizations speak less to actual implementation and legal mechanics and more to a vigorous commitment to transparency.

\section{Conclusion}

The nature of governance leaves all laws prone to disappointment; lapses in application and interpretive decay affect every law. They generally undergo changes, often diminishment, through court decisions and agency rulemaking. Laws rarely arrive fully realized and without issues in application. Some laws, however, are more acutely predisposed to internal resistance and efforts to decay; one category being oversight laws and laws that seek to implement accountability and transparency. In seeking to affect transparency and potentially conceal incriminating or embarrassing information, government offices and officials are highly motivated to circumvent or even violate FOI laws. When a law is likely to meet resistance in application, compliance is loosely enforced and penalties effectively nonexistent, public officers have and will choose to risk an unlikely penalty.

FOI laws are the host of both inherent frictions and deliberate frustrations. Again, this is the nature of implementing a difficult law, but too often deliberate frustrations are allowed to masquerade as inherent frictions. Herd \& Moynihan have done away with the dichotomy; whether a naturally occurring difficulty in application or an intentional effort to undermine the law, both are failures to realize the purpose of the law. In following this logic, it is no surprise that variables that represent independent oversight and positive intentions proved to be the strongest predictors in the study. The laws are so inconsistent and erratic in application that general variables proving the best predictors is logical when these variables are taken as signals of sincerity.

\section{Limitations}

The audit and regression analyses do not allow for any assumptions of causation. There are undoubtedly many factors at play that are not considered in the statistical model. As discussed below, developing a culture of transparency is the elusive goal in FOI compliance. This study is only able to point to relationships that coexist between legal factors and FOI and outcomes and processes, and not make any observations about cause and effect. And while the findings may play a role in growing a culture of transparency, it is limited as there are surely many non-legal factors that drive FOI compliance.

One of the study's primary limitations lies in its effort to quantify the law. The law is ambiguous. Statutes never tell the whole story, failing to explain an operational element or fully define a pivotal term. Judicial interpretation adds necessary nuance but often manifests sporadically in implementation. The study is guilty of measuring rough and obvious quantitative outcomes and drawing declarative conclusions, a practice warned against by Pozen (2020), Michener (2019), and Cucciniello et al. (2017). This limitation is both compounded and conflated with the general disregard for FOI laws. However, this should not discourage future research in this area. Scholars should redouble their efforts in trying to pin down the law and what makes it work. Continued collaboration between conventional legal research with quantitative analysis has the potential to affect positive changes in FOI laws. And as a globally popular transparency mechanism, advances in this marriage of conventional legal research and quantitative analysis could bear democratic fruit. 
The study is also limited by the possibility of the Hawthorne effect, whereby an experiment is tainted by subjects' awareness of the experiment (Adair, 1984). Though the project is not a true experiment, there were multiple instances where it became clear county custodians were discussing requests with custodians in other counties. How this impacted the study and to what degree is difficult to ascertain. However, the study sought to test and measure compliance with the law, and consultation with others is well within the law and could even be viewed as a positive.

The findings suggest cultivating a culture of transparency may be as or more important than conventional legal variables like deadlines or penalties. The primary conclusion of the study is the problematic nature of modern FOI implementation. It is exceptionally difficult to glean what benefits or impedes better FOI outcomes, when the laws are disregarded with impunity. At their most fundamental, FOI laws are clerical. They are designed to be transactional; simple, routine "paperpushing" mechanisms that provide a window into government activity, and only a small share of requests should meet suspicion or denial. Though the majority of requests encounter well-intentioned custodians and successful ends, there is still a substantial amount of disinterest and hostility in FOI processes. And were the study to have considered more controversial records, surely the results would have been poorer. If the government and public are to realize the lofty covenant aspired to in the preambles of these laws - and not allow them to exist as hollow platitudes and empty appeals to democratic ideals - further effort is needed to produce a culture of transparency. Resting on the current state of these laws, saddled with administrative burdens, will not bring it about. The findings suggest it starts with more vigilance and a more willing legislature. 


\section{References}

AbouAssii, K., \& Nabatchi, T. (2019). A snapshot of FOIA administration: Examining recent trends to inform future research. The American Review of Public Administration, 49(1), 21-35, https://doi.org/10.1177/0275074018771683

Adair, J. G. (1984). The Hawthorne effect: A reconsideration of the methodological artifact. Journal of Applied Psychology, 69(2), 334-345, https://doi.org/10.1037/0021-9010.69.2.334

Bashir, M., \& Nisar, M. A. (2020). Expectation versus reality: Political expediency and implementation of right to information laws. Public Administration Quarterly, 44(1), 3-30, https://paq.spaef.org/article/1917/Expectation-Versus-Reality-Political-ExpediencyandImplementation-of-Right-to-Information-Laws

Ben-Aaron, J., Denny, M., Desmarais, B., \& Wallach, H. (2017). Transparency by conformity: A field experiment evaluating openness in local governments. Public Administration Review, 77(1), 68-77, https://doi.org/10.1111/puar.12596

Blair, T. (2010). A Journey: My Political Life. London, UK: Knopf Publishers.

Committee on Oversight and Government Reform. (2016). FOIA Is Broken: A Report. U.S. House of Representatives. Retrieved from https://republicans-oversight.house.gov/wpcontent/uploads/2016/01/FINAL-FOIA-Report-January-2016.pdf

Cucciniello, M., Porumbescu, G. A., \& Grimmelikhuijsen, S. (2017). 25 Years of transparency research: Evidence and future directions. Public Administration Review, 77(1), 32-44, https://doi.org/10.1111/puar.12685

Cuillier, D. (2019). Bigger stick, better compliance? Testing strength of public record statutes on agency transparency in the United States. Presented at the Global Conference on Transparency Research. Rio de Janeiro, Brazil. Retrieved from https://eventos.fgv.br/en/6deg-global-conference-transparency-research/executive-andadvisory-committe

Cuillier, D. (2010). Honey v. vinegar: Testing compliance-gaining theories in the context of freedom of information laws. Communication Law and Policy, 15(3), 203-229, https://doi.org/10.1080/10811680.2010.489842

Danielson, L. (2012). Giving teeth to the watchdog: Optimizing open records appeals processes to facilitate the media's use of FOIA laws. Michigan State Law Review, 2012(3), 980-1055, https://digitalcommons.law.msu.edu/lr/vol2012/iss3/5

Dolan, J. (2018, March 21). L.A. County has repeatedly violated state open records laws, L.A. Times lawsuit alleges. Los Angeles Times. Retrieved from https://www.latimes.com/local/lanow/lame-ln-county-records-lawsuit-20180321-story.html

Fausset, R. (2019, Dec. 19). Former Atlanta press secretary is found guilty of violating Open Records Acts. New York Times. Retrieved from: https://www.nytimes.com/2019/12/19/us/jennagarland-open-records-atlanta.html

Feinberg, L. E. (1986). Managing the Freedom of Information Act and federal information policy. Public Administration Review, 46(6), 615-621, https://www.jstor.org/stable/976227

Fenster, M. (2015). The informational ombudsman: Fixing open government by institutional design. Revue Internationale des Governments Ouverts, 6, 275-296, https://papers.ssrn.com/sol3/papers.cfm?abstract_id=3022914

Georgia Open Records Act, Ga. Code Ann. $§ \quad 50-18-70 \quad$ (2020), https://law.georgia.gov/sites/law.georgia.gov/files/imported/vgn/images/portal/cit_1210/62/ 51/186385699r1.pdf 
Georgia Department of Law. (2012, April 17). Governor Deal signs HB 397, revamping Georgia's sunshine laws. Retrieved from https://law.georgia.gov/press-releases/2012-04-17/governordeal-signs-hb-397-revamping-georgias-sunshine-laws

Grabell, M. (2016, July 21). Delayed, denied, dismissed: Failures on the FOIA front. ProPublica. Retrieved from https://www.propublica.org/article/delayed-denied-dismissed-failures-onthe-foia-front\#michael-grabell

Grimmelikhuijsen, S., John, P., Meijer, A., \& Worthy, B. (2018). Do freedom of information laws increase transparency of government? A replication of a field experiment. Journal of Behavioral Public Administration, 1(2), 1-10, http://www.journalbpa.org/index.php/jbpa/article/view/34

Hazell, R., \& Worthy, B. (2010). Assessing the performance of freedom of information. Government Information Quarterly, 27(4), 352-359, https://doi.org/10.1016/j.giq.2010.03.005

Herd, P., \& Moynihan D. P. (2018). Administrative burden: Policymaking by other means. New York, NY: Russell Sage Foundation.

Jenkins, N. R., Landgrave, M., \& Martinez, G. E. (2020). Do political donors have greater access to government officials? Evidence from a FOIA field experiment with U.S. municipalities. Journal of Behavioral Public Administration, 3(2), 1-17, http://www.journalbpa.org/index.php/jbpa/article/view/111

Jones, N. (2015, March 13). Unnecessary Freedom of Information Act fees. Reporters Committee for Freedom of the Press. Retrieved from http://sunshineweek.rcfp.org/unnecessaryfreedom-of-information-act-fees

Klepal, D., \& Deere, S. (2018, March 13). Attorney general launches criminal probe of city texts. Atlanta Journal-Constitution. Retrieved from https://www.ajc.com/news/local-govt-politics/attorney-general-launches-criminal-probe-city-halltexts/uVloyrbVZ5IL7fPOXTHFrL/

Marzen, C. (2018). Public records denials. New York University Journal of Law and Liberty, 11(3), 966-1,027, https://www.nyujll.com/volume-11/blog-post-title-two-37fjy

Mendel, T. (2003). Freedom of information as an intentionally protected human right. Comparative Media Law Journal, 1(1), 39-70.

Michener, G. (2019). Gauging the impact of transparency policies. Public Administration Review, 79(1), 136-139, https://doi.org/10.1111/puar.13011

Michener, G., Velasco, R. B., Contreras, E., \& Rodrigues, K. F. (2020). Googling the requester: Identity-questing and discrimination in public service provision. Governance, 33(2), 249267, https://doi.org/10.1111/gove.12416

Piotrowski, S. J., \& Van Ryzin, G. G. (2007). Citizen attitudes toward transparency in local government. The American Review of Public Administration, 37(3), 306-323, https://doi.org/10.1177/0275074006296777

Pozen, D. E. (2020). Seeing transparency more clearly. Public Administration Review, 80(2), 326331, https://doi.org/10.1111/puar.13137

Qiu, Y., Zubak-Skees, C., \& Lincoln, E. (2015, Nov. 9). How does your state rank for integrity? Center for Public Integrity. Retrieved from https://publicintegrity.org/politics/statepolitics/state-integrity-investigation/how-does-your-state-rank-for-integrity/

Roberts, J. A. (2017, June 1). Seven things to know about how Colorado's open records law is changing. Colorado Freedom of Information Coalition. Retrieved from https://coloradofoic.org/seven-things-know-colorado-records-law-changing/

Schudson, M. (2015). The Rise of the Right to Know: Politics and the Culture of Transparency, 1945 1975. Cambridge, MA: Harvard University Press. 
Spac, P., Voda, P., \& Zagrapan, J. (2018). Does the freedom of information law increase transparency at the local level? Evidence from a field experiment. Government Information Quarterly, 35(3), 408-417, https://doi.org/10.1016/j.giq.2018.05.003

Stewart, D. R. (2010). Let the sunshine in, or else: An examination of the "teeth" of state and federal open meetings and open records laws. Communication Law and Policy, 15(3), 265-310, https://doi.org/10.1080/10811680.2010.489858

The FOIA Project. (2020.) Issue Search. Transactional Records Access Clearing House. Retrieved from http://foiaproject.org/issue_search/\#

Thompson, E. (2017, March 11). State public records law poses challenge after overhaul. Telegram \& Gazette. Retrieved from https://www.telegram.com/news/20170311/state-public-recordslaw-poses-challenge-after-overhaul

Trubey, J. S. (2019, Dec. 19). Ex-Reed aide first official convicted of public records violations. Atlanta Journal-Constitution. Retrieved from https://www.ajc.com/news/reed-aide-firstofficial-convicted-public-records-violations/ImqpLWZLh9aMU89t6vcwtI/

Wilks, A. G. (2020, March 15). Despite new law, SC cities, counties are charging thousands of dollars for public records. The Post and Courier. Retrieved from https://www.postandcourier.com/news/despite-new-law-sc-cities-counties-are-chargingthousands-of-dollars-for-public-records/article_74c11f4c-6468-11ea-ba8a7bbef56f5689.html

Worthy, B. (2017). The Politics of Freedom of Information: How and Why Governments Pass Laws that Threaten Their Power. Manchester, UK: Manchester University Press.

Worthy, B., John, P., Vannoni, M. (2017). Transparency at the parish pump: A field experiment to measure the effectiveness of freedom of information requests in England. Journal of Public Administration Research and Theory, 27(3), 485-500, https://doi.org/10.1093/jopart/muw063 